Article

\title{
Subjective Oral Health in Dutch Adults
}

\section{Gijsbert H.W. Verrips ${ }^{1,2, *}$ and Annemarie A. Schuller ${ }^{2}$}

1 Academic Centre Dentistry Amsterdam, Gustav Mahlerlaan 3004, 1081 LA Amsterdam, The Netherlands

2 TNO, PO Box 2215, 2301 CE Leiden, The Netherlands; E-Mail: annemarie.schuller@tno.nl

* Author to whom correspondence should be addressed; E-Mail: erik.verrips@tno.nl;

Tel.: +31631792882.

Received: 29 March 2013; in revised form: 16 April 2013 / Accepted: 24 April 2013 /

Published: 6 May 2013

\begin{abstract}
Aim: To determine whether the subjective oral health (SOH) of the Dutch adult population was associated with clinical and demographic variables. Methods: A clinical examination was conducted in a sample of 1,018 people from the Dutch city of 's-Hertogenbosch. SOH was measured using the Dutch translation of the short form of the Oral Health Impact Profile (OHIP-NL14). Results: The average score on the OHIP-NL14 was $2.8 \pm 5.9$ and $51 \%$ of the respondents had a score of 0 . Dental status was the most important predictor of $\mathrm{SOH}$. Conclusions: The $\mathrm{SOH}$ in the Dutch adult population was much better than in groups of adults in Australia, the United Kingdom and New Zealand. Nevertheless, there were important variations in $\mathrm{SOH}$ related to dental and socio-economic status.
\end{abstract}

Keywords: subjective oral health; dental status; socio-economic status; adults

\section{Introduction}

In medicine, mortality and morbidity are no longer the only relevant outcomes of prevention, cure and care. In recent decades, patient-reported outcomes (PRO), such as health-related quality of life, have rapidly grown in importance [1]. Also in dentistry, the focus on oral health-related quality of life 
(OHQoL) as a PRO has greatly expanded [2,3]. In part, this interest has to do with the emancipatory view that patient perspectives should be taken into account in decision making about policy and treatment options. However, in the literature the meaning and definition of OHQoL is the subject of serious debate [4-6]. Moreover, the growing number of instruments available aimed at measuring OHQoL [7-12] only adds to the confusion. Despite such problems in definition and measurement, the consensus in the literature on the relevance of PRO in dentistry is beyond question [2,13]. Also in dental epidemiology, measurement of PRO is receiving growing attention [14-18].

In several recent studies in clinical populations, an association of clinical parameters with subjective oral health (SOH) was reported [19-26]. We included self-reported $\mathrm{SOH}$ as a PRO in a large scale dental epidemiologic study in the Netherlands, performed in 2007. Results of the clinical study were presented elsewhere [17] .

The aim of the present study was to determine whether the $\mathrm{SOH}$ of the adult Dutch population is associated with variables such as a dentate or edentate mouth, caries experience, age, supplementary dental insurance, socio-economic status and last dental visit.

\section{Materials and Methods}

Population and sample: The population of 's-Hertogenbosch was assumed to be representative for the Netherlands. A sample was taken from the policyholder database of the health insurer VGZ-IZA in 's-Hertogenbosch. It comprised 6,750 people in the 25-74 age category. They received a letter explaining the aim of the study and informing them that an interviewer would be visiting. There were personal contacts with 4,533 people (69\%), 36\% of whom completed a questionnaire during the visit. The majority by far completed the section for dentate respondents $(87 \%)$, with the other $13 \%$ completing the section for edentate respondents. Subsequently, the dentate respondents were asked to participate in a clinical oral examination. In the end, a clinical examination could be conducted in 1,018 people ( $72 \%$ of the dentate respondents who completed a questionnaire). This paper reports on survey data for 1,580 respondents and clinical data for 1,018 respondents. Both survey and clinical data were available for 975 respondents. Table 1 shows the number of respondents for whom data were available. Details of the sampling procedure can be found in a report covering the total study [17]. The study was approved by the Medical Ethics Committee of the Leiden University Medical Centre.

Measurements: The clinical data were collected in a study vehicle equipped for that purpose, by calibrated dental researchers. Caries experience was expressed in a DMFT-score (the sum of Decayed, Missing, or Filled Teeth). Demographic and social variables were recorded using a questionnaire. Level of education was stratified into low and high, based upon the intellectual challenges the educational system in the Netherlands poses. Generally, people with a low education had 10 years of education or less; people with a high level of education had at least 12 years of education. In the Netherlands, in the last decades, it has been common to have at least one dental visit yearly. Therefore, regularity of dental visits was stratified into having had the last dental visit less than a year ago versus less recently. 
The study produced scores for SOH using the Dutch translation of the short form of the Oral Health Impact Profile (OHIP-NL14) [18]. A minimum score of 0 indicates perfect $\mathrm{SOH}$ and a maximum score of 56 the worst possible $\mathrm{SOH}$.

Analysis: The association between $\mathrm{SOH}$ and the other study variables was determined using univariate analysis of variance. Given the fact that it was reasonable to expect correlations between the study variables, Pearson correlation coefficients were calculated. Finally, a multiple linear regression analysis was performed, with $\mathrm{SOH}$ as a dependent variable. A p value $<0.05$ was considered statistically significant.

\section{Results}

The average total score on the OHIP-NL14 was $2.8 \pm 5.9$. The distribution was very skewed: Fifty one percent of the respondents had a total score of 0 . The average OHIP-NL14 score of the respondents with a score higher than 0 , was $5.7 \pm 7.3$. The minimum score was 0 and the maximum score was 50. In subjects reporting one or more problems, the five most prevalent problems were: painful aching in mouth (30\%), uncomfortable to eat any foods $(24 \%)$, self-conscious (18\%), a bit embarrassed (15\%) and tense (14\%). All other problems had a prevalence of less than $10 \%$.

Unfortunately, not all data were available for all participants. It emerges from Table 1 that all the study variables were related statistically significant to the total score from the OHIP-NL14, with the exception of the supplementary insurance for dental care. Edentulous adults had a worse SOH rating than dentulous subjects; those with a DMFT > 10 had a worse SOH than those with less DMFT. The 25-34 year-olds had better SOH than older participants. Highly educated adults had better SOH than those with a lower education. Those who had visited the dentist within the last year, had a better $\mathrm{SOH}$.

$\mathrm{SOH}$ was most strongly related to dental status. This was confirmed in the regression analysis: the only statistically significant predictor was dental status $(\mathrm{B}=1,62 ; 0.90<\mathrm{B}<2.36)$. The total regression model explained $4 \%$ of the variance in OHIP-NL14. 
Table 1. Lists of all available data relating to the study variables. Number of respondents with data available (n), average OHIP-NL14 value with standard deviation (X), 95\% confidence interval $(95 \% \mathrm{CI})$ and $\mathrm{p}$ value for ANOVA (p) for each study variable.

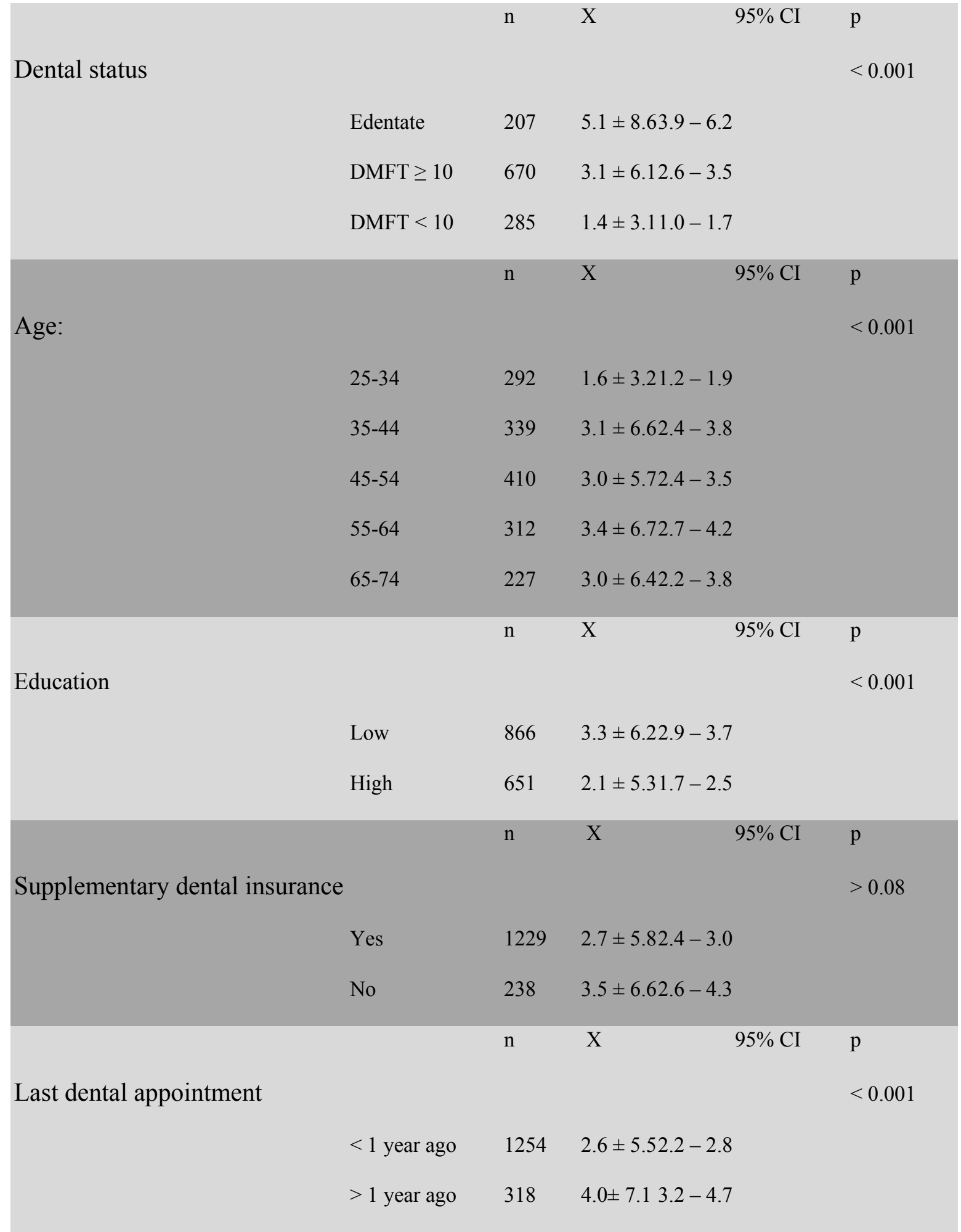


Table 2. Shows the Pearson correlations between all study variables. Correlation matrix OHIP-NL14 and study variables $(n=975)$

\begin{tabular}{|c|c|c|c|c|c|}
\hline & HIP-NL14 & Dental status & Age & $\begin{array}{l}\text { Education } \\
\text { Insurance }\end{array}$ & $\begin{array}{l}\text { Supplementary Dental } \\
\text { appointment }\end{array}$ \\
\hline OHIP-NL14 & 1 & & & & \\
\hline Dental status & 0.2 & 1 & & & \\
\hline Age: & 0.1 & 0.5 & 1 & & \\
\hline Education & -0.1 & -0.3 & -0.2 & 1 & \\
\hline \multicolumn{6}{|c|}{ Supplementary } \\
\hline Insurance & -0.1 & -0.2 & 0 & 0.1 & 1 \\
\hline Dental app. & -0.1 & 0.4 & 0 & 0 & -0.2 \\
\hline
\end{tabular}

\section{Discussion}

In 2004, Steele et al. reported an average OHIP-14 score of 7.4 for dentate adults in Australia and 5.1 in the United Kingdom [14]. Nuttal et al. (2011) reported an average OHIP-14 score of 17.4 in England in 2009 [15]. It would be valuable to directly compare the latest British and Dutch oral health and OHIP-14 data in a further study. In such a study, more detailed analyses of clinical oral health and subjective oral health is called for. Furthermore, as both the British and the Dutch data are from recent large scale epidemiologic studies, issues of selective dropout may be addressed in further detail. Lawrence et al. (2008) found an average OHIP-14 score of 8 in a cohort of dentate 32-year-olds in New Zealand [17]. The present study showed that half of the adult Dutch population, including edentate adults, reported no negative subjective oral health whatsoever. The average OHIP-NL14 score was 2.8. The $\mathrm{SOH}$ for the Dutch adult population was therefore much better than for groups of adults in Australia, the United Kingdom and New Zealand.

Nevertheless, there were major variations in the Netherlands for $\mathrm{SOH}$ in different groups. Edentates had a distinctly worse $\mathrm{SOH}$ than dentates and dentates with a DMFT score of less than 10 had the best SOH. Steele et al. also (2004) found a strong link between dental status and SOH [14]. Good dental health is therefore not only clinically relevant in dental terms, but it also results in a fewer subjectively perceived problems with oral health.

It also emerged that people with lower education had relatively poor $\mathrm{SOH}$. Socio-economic health shortfalls among people with lower education are not only associated with poor oral health but also, as a result, with poorer $\mathrm{SOH}$. This underlines once again the importance of policy focusing on reducing health inequalities of this kind.

Not everyone who was invited to participate in the study did so. It is known that non-participants generally have poorer oral health than participants. The results of the study therefore probably sketch an over-positive picture. As suggested earlier, this could be a focal point in a joint analysis effort of the British and Dutch studies. 
Some authors have questioned the validity of the OHIP, because it is not certain that this questionnaire actually measures what it is meant to measure. Many authors use this instrument as a measure of OHRQoL. However, the developers never made such a claim. We feel the OHIP is a measure of SOH rather than of OHRQoL. Moreover, Verrips [13] and Kieffer et al. [4] pointed out that the OHIP is actually a combination of causes and consequences, or effects, of SOH. Despite these objections, using the OHIP allows for international comparisons, because it is internationally by far the instrument of choice. Further study of the validity of the OHIP (and other instruments) is desirable to make more valid measurements of OHRQoL and $\mathrm{SOH}$ possible. Nevertheless, it is patently obvious that - despite the limitations of the currently available instruments - a clinically healthy mouth correlates with a better SOH. Only by longitudinal study can we clarify the causality between a healthy mouth and $\mathrm{SOH}$.

\section{Conflict of Interest}

The authors declare no conflict of interest.

\section{References}

1. Moons, P.; Budts, W.; De Geest, S. Critique on the Conceptualisation of Quality of Life: A Review and Evaluation of Different Conceptual Approaches. Int. J. Nurs. Stud. 2006, 43, 891901.

2. Verrips, G.H.; Schuller, A.A. The Impact of Oral Health on Quality of Life of Dutch Adults. Ned. Tijdschr. Tandheelkd. 2011, 118, 162-164.

3. Skaret, E.; Berg, E.; Raadal, M.; Kvale, G. Reliability and Validity of the Dental Satisfaction Questionnaire in a Population of 23-Year-Olds in Norway. Community Dent. Oral Epidemiol. 2004, 32, 25-30.

4. Kieffer, J.M.; Verrips, G.H.; Hoogstraten, J. The Complexity of the Concept Oral HealthRelated Quality of Life. Ned. Tijdschr. Tandheelkd. 2011, 118, 142-144.

5. Locker, D.; Allen, F. What do Measures of 'Oral Health-Related Quality of Life' Measure? Community Dent. Oral Epidemiol. 2007, 35, 401-411.

6. van Wijk, A.J. Quality of Life is a Dynamic Concept. Ned. Tijdschr. Tandheelkd. 2011, 118, 126-128.

7. Strauss, R.P.; Hunt, R.J. Understanding the Value of Teeth to Older Adults: Influences on the Quality of Life. J. Am. Dent. Assoc. 1993, 124, 105-110.

8. Slade, G.D.; Spencer, A.J. Development and Evaluation of the Oral Health Impact Profile. Community Dent. Health 1994, 11, 3-11.

9. Slade, G.D.; Hoskin, G.W.; Spencer, A.J. Trends and Fluctuations in the Impact of Oral Conditions among Older Adults during a One Year Period. Community Dent. Oral Epidemiol. 1996, 24, 317-321.

10. Kressin, N.R. Associations among Different Assessments of Oral Health Outcomes. J. Dent. Educ. 1996, 60, 501-507. 
11. Adulyanon, S.; Vourapukjaru, J.; Sheiham, A. Oral Impacts Affecting Daily Performance in a Low Dental Disease Thai Population. Community. Dent. Oral Epidemiol. 1996, 24, 385-389.

12. Leao, A.; Sheiham, A. The Development of a Socio-Dental Measure of Dental Impacts on Daily Living. Community Dent. Health 1996, 13, 22-26.

13. Verrips, G.H.W. Think Bigger.; Vossiuspers: Amsterdam, 2008.

14. Steele, J.G.; Sanders, A.E.; Slade, G.D.; Allen, P.F.; Lahti, S.; Nuttall, N.; Spencer, A.J. How do Age and Tooth Loss Affect Oral Health Impacts and Quality of Life? A Study Comparing Two National Samples. Community Dent. Oral Epidemiol. 2004, 32, 107-114.

15. Nuttal, N.; Tsakos, G.; Lader, D.; Hill, K. Outcome and impact - a report from the Adult Dental Health Survey 2009; The Health and Social Care Information Centre, UK, 2011.

16. Gagliardi, D.I.; Slade, G.D.; Sanders, A.E. Impact of Dental Care on Oral Health-Related Quality of Life and Treatment Goals among Elderly Adults. Aust. Dent. J. 2008, 53, 26-33.

17. Lawrence, H.P.; Thomson, W.M.; Broadbent, J.M.; Poulton, R. Oral Health-Related Quality of Life in a Birth Cohort of 32-Year Olds. Community Dent. Oral Epidemiol. 2008, 36, 305-316.

18. Schuller, A.A. Mondgezondheid Van Volwassenen 2007.; TNO: Leiden, 2010.

19. van der Meulen, M.J.; Lobbezoo, F.; John, M.T.; Naeije, M. Oral Health Impact Profile. an Instrument for Measuring the Impact of Oral Health on the Quality of Life. Ned. Tijdschr. Tandheelkd. 2011, 118, 134-139.

20. de Jongh, A.; Cheung, S.; Khoe, L.H.; Asmi, N.E. Cosmetic Dental Treatment. its Impact on Happiness and Quality of Life. Ned. Tijdschr. Tandheelkd. 2011, 118, 152-155.

21. Versloot, J.; Klaassen, M.A. Quality of Life and Oral Health in Children. Ned. Tijdschr. Tandheelkd. 2011, 118, 158-160.

22. Vermaire, J.H. Treatment of Dental Phobia and Quality of Life. Ned. Tijdschr. Tandheelkd. 2011, 118, 187-189.

23. Teeuw, W.J.; Abhilakh Missier, A.V.; Hartman, M.; Ton, M.; Schuller, A.A.; Verrips, G.H.; Loos, B.G. Periodontal Disease and Quality of Life. Ned. Tijdschr. Tandheelkd. 2011, 118, 199-201.

24. Gerritsen, A.E.; Creugers, N.H. Quality of Life Associated with Tooth Loss and Tooth Replacement. Ned. Tijdschr. Tandheelkd. 2011, 118, 210-213.

25. Papagianni, C.E.; van der Meulen, M.J.; Naeije, M.; Lobbezoo, F. Oral Kinesiology and the Quality of Life. Ned. Tijdschr. Tandheelkd. 2011, 118, 145-147.

26. Raghoebar, G.M.; Meijer, H.J.; Visser, A.; Vissink, A. Quality of Life and Treatments with Oral Implants. Ned. Tijdschr. Tandheelkd. 2011, 118, 149-151.

(C) 2013 by the authors; licensee MDPI, Basel, Switzerland. This article is an open access article distributed under the terms and conditions of the Creative Commons Attribution license (http://creativecommons.org/licenses/by/3.0/). 